\title{
Generation of a fluorescent oncoprotein in soluble form and its delivery into mammalian cells
}

\author{
Motevalli F, Khodaei A, Anvari M, Bolhassani A \\ Department of Hepatitis and AIDS, Pasteur Institute of Iran, Tehran, Iran. azam.bolhassani@yahoo.com
}

\begin{abstract}
BACKGROUND: Protein fusion technology was widely used to improve expression, purification and solubility of the recombinant proteins expressed in $E$. coli for in vitrolin vivo delivery.

METHODS: We developed a method for successful expression of soluble +36GFP-A2-E7 protein in E. coli and its effective delivery into mammalian cells. At first, the plasmid harboring +36GFP-A2-E7 was transformed into E. coli Rosetta competent cells. Then, the recombinant protein fused to histidine tag was expressed and purified using affinity chromatography. Different conditions such as inducer dose, time and temperature of induction, $\mathrm{pH}$ and urea concentration were evaluated. Finally, the delivery of the recombinant protein was detected in HEK-293T cells using fluorescent microscopy and flow cytometry.

RESULTS: Our data showed that the expressed protein formed inclusion bodies at $37^{\circ} \mathrm{C}$ and $3 \mathrm{~h}$ post-induction. The soluble protein was generated using $0.5 \mathrm{mM}$ IPTG and growth at $16{ }^{\circ} \mathrm{C}$ for $20 \mathrm{~h}$, and purified by low concentrations of urea and $200 \mathrm{mM}$ imidazole. The soluble fraction of +36GFP-A2-E7 protein could significantly represent higher fluorescent property and stronger delivery into mammalian cells compared to the insoluble form. CONCLUSION: Generally, soluble form of fusion protein retained its biological activity and could directly penetrate into the cells without the fusion tags (Tab. 1, Fig. 7, Ref. 23). Text in PDF www.elis.sk.

KEY WORDS: HPV, E7, +36 GFP, E. coli expression system, transfection.
\end{abstract}

\section{Introduction}

Escherichia coli (E. coli) is still one of the most commonly convenient production systems because of low cost, efficiency, suitability for large-scale cultivation and easy manipulation (1). However, over-expression of the recombinant non-bacterial proteins in E. coli (higher than $2 \%$ of cellular protein) led to misfolding or incomplete folding processes. These structures could be accumulated as insoluble aggregates found in both the cytoplasmic and periplasmic spaces of $E$. coli as so-called inclusion bodies (1-3). Although, the expression of protein as inclusion bodies has a high yield, the procedures for separation, washing and solubilization of inclusion bodies and native form of the recombinant heterologous protein are often time-consuming and difficult $(4,5)$. The recent studies showed that a large part of proteins in inclusion bodies is functional and thus can be used for multiple applications without being solubilized and refolded (6). However, several strategies are available to minimize the formation of inclusion bodies such as manipulation of growth temperature, medium composition, dose of inducer, induction time, and plasmid-related properties including promoter, copy number and host strain. For some pro-

Department of Hepatitis and AIDS, Pasteur Institute of Iran, Tehran, Iran Address for correspondence: A. Bolhassani, $\mathrm{PhD}$, Department of Hepatitis and AIDs, Pasteur Institute of Iran, Tehran, Iran.

Phone: +98.21.66953311, Fax: +98.21.66465132 teins, these strategies were ineffective to get a soluble product ( 7 , 8). As known, the green fluorescent protein (GFP) could be used to generate fluorescent fusion proteins. Most GFP fusion proteins were constructed by placing GFP at either $\mathrm{N}$ - or C-terminus of the host protein. These structures could damage the function of some host proteins. Another approach was tested to insert GFP into the middle of the host protein. However, finding a suitable site for insertion of GFP was problematic and time-consuming (9). Thus, the production of some GFP fusion proteins was often performed in eukaryotic expression systems such as insect or yeast $(10,11)$. In this study, we attempted to generate a biologically active fluorescent fusion protein in an E. coli system. We used a superpositively charged protein, so-called +36 GFP, that can deliver across negatively charged cell membrane without commercial transfection reagents (12). Herein, +36 GFP-E7 fusion protein was generated in an E. coli system. E7 is an oncoprotein containing 294 amino acid residues. It plays an important role in the survival of human papillomavirus (HPV) (13). In this study, purification of inclusion bodies followed by solubilization without disturbing its structure and refolding was applied for the recovery of GFP $(+36)$-E7 from E. coli. This fusion protein was expressed as inclusion bodies with His-tag in E. coli and was used for the recovery of bioactive protein using novel purification procedure. In general, this study provides a method to produce sufficient amounts of soluble and active +36 GFP-A2-E7 protein using E. coli expression system for HPV vaccine development. 


\section{Materials and methods}

Cloning, expression and identification of pET28a-GFP (+36)2A-E7

The 2A peptide (VKQTLNFDLLKLAGDVESNPGP) (14, 15) and HPV E7 $(16,17)$ sequences were obtained from NCBI databank. The 2A peptides are 18-22 amino-acid (aa)-long viral oligopeptides that mediate "cleavage" of polypeptides during translation in eukaryotic cells (18). The 2A-E7 was digested from pUC57-2A-E7 (synthesized by BioMatik company, Canada) using EcoRI/ HindIII restriction enzymes, and subcloned into the same sites in pET26-GFP $(+36)$ (previously provided in our laboratory (12)) as follows:

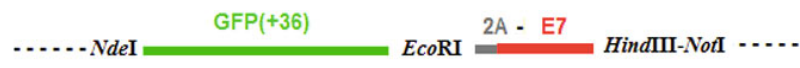

A volume of $5 \mu \mathrm{L}$ of $\mathrm{pET}$-GFP (+36)-2A-E7 plasmid was purified by plasmid purification kit to transform $100 \mu \mathrm{L}$ E. coli Rosetta. The E. coli Rosetta carrying pET-GFP (+36)-2A-E7 was grown overnight on LB plates containing $50 \mu \mathrm{g} / \mathrm{mL}$ kanamycin at $37{ }^{\circ} \mathrm{C}$. The cultures were grown at $37^{\circ} \mathrm{C}$ in Ty $2 \mathrm{X}$ medium to mid-log phase [Optical Density (OD) of 0.5 at a wavelength of $600 \mathrm{~nm}]$ and the expression of the recombinant protein was induced using IPTG to a final concentration of $1 \mathrm{mM}$ at $37^{\circ} \mathrm{C}$ for 3 hours. The E. coli cells were harvested by centrifugation and $20 \mu \mathrm{L}$ of the cell pellet including both lysed supernatant and the whole cells was taken and $20 \mu \mathrm{L}$ of $2 \mathrm{X}$ SDS sample buffer was added to the mixture. The samples were heated for $10 \mathrm{~min}$ at 95 ${ }^{\circ} \mathrm{C}$ and subjected to SDS-PAGE. Western blotting was performed to identify the recombinant protein using anti-E7 monoclonal antibody as mentioned previously $(16,17)$. The recombinant protein was visualized using $\mathrm{DAB} / \mathrm{H}_{2} \mathrm{O}_{2}$ substrate (Roche, Switzerland).

\section{Solubility assay}

Rosetta (DE3) competent cells containing pET28a-GFP (+36)2A-E7 were grown overnight at $37{ }^{\circ} \mathrm{C}$ and $500 \mu \mathrm{L}$ of an overnight culture was inoculated into $50 \mathrm{ml}$ of fresh Ty2X medium and grown to an $\mathrm{OD}_{600}=\sim 0.6$ at $37{ }^{\circ} \mathrm{C}$. The expression of the recombinant protein was induced by $1 \mathrm{mM}$ IPTG (isopropyl- $\beta$ D-thiogalactopyranoside), and the cells were grown at $37^{\circ} \mathrm{C}$ for 3 hours. The cells were then harvested by centrifugation at 6,000 $\mathrm{g}$ for $20 \mathrm{~min}$, and the cell pellets were suspended in PBS1X. Following incubation on ice for $60 \mathrm{~min}$, the cells were sonicated at $200 \mathrm{~W}$ (10 times for $10 \mathrm{~s}$ ) using Uibra cell TM sonicator (Sonics \& Materials, Newtown, CT, US) and bacterial pellets were harvested at $10,000 \mathrm{~g}$ for $20 \mathrm{~min}$. The soluble fraction (supernatant) was analyzed by SDS-PAGE. The insoluble fraction (pellet) was resuspended in lysis buffer, the process was repeated three times and the supernatants were analyzed by SDS-PAGE and Coomassie blue staining.

Solubilization of the recombinant GFP $(+36)-2 A-E 7$ protein under various conditions (temperature and inducer dose)

For the extensive solubility assay, the extraction conditions were optimized to express the recombinant GFP (+36)-2A-E7 protein. Herein, Rosetta cells expressing the recombinant protein were grown in a baffled flask containing $250 \mathrm{ml}$ of the culture medium and induced at $20^{\circ} \mathrm{C}$ for $16 \mathrm{~h}, 28{ }^{\circ} \mathrm{C}$ for $5 \mathrm{~h}, 37^{\circ} \mathrm{C}$ for $3 \mathrm{~h}$ by adding various concentrations of IPTG inducer $(0.1 \mathrm{mM}$, $0.5 \mathrm{mM} \& 1 \mathrm{mM})$. The harvested cells were suspended in $25 \mathrm{ml}$ of lysis buffer ( $50 \mathrm{mM}$ Tris- $\mathrm{HCl}, \mathrm{pH}=8,0.5 \mathrm{mM}$ EDTA, $0.1 \%$ Triton X-100, $0.1 \%$ Tween $20,1 \mathrm{mg} / \mathrm{ml}$ lysozyme, $1 \mathrm{X}$ protease inhibitor cocktail) and subjected to three freeze-thaw cycles in liquid nitrogen and cold water $\left(4-10{ }^{\circ} \mathrm{C}\right)$. The cell suspension was sonicated by 3 bursts of $30 \mathrm{~s}$ each at $60 \%$ maximal power and then centrifuged at 10,000 g for $20 \mathrm{~min}$. A fixed amount of inclusion bodies was solubilized at a given temperature or inducer concentration. The soluble (supernatant) fraction was analyzed by SDS-PAGE and the amount of solubilization was also measured at different conditions by spectrofluorometry.

\section{Solubilization of the recombinant GFP $(+36)-2 A-E 7$ protein in different $\mathrm{pH}$ conditions}

The harvested cells from protein expression at the optimal conditions was suspended in lysis buffer $(50 \mathrm{mM}$ Tris- $\mathrm{HCl} \mathrm{pH}=8,0.5$ mM EDTA, $0.1 \%$ Triton X-100, 0.1 \% Tween 20, 10 mM DTT, 1 $\mathrm{mg} / \mathrm{ml}$ lysozyme, $1 \mathrm{X}$ protease inhibitor cocktail) and subjected to three freeze-thaw cycles in liquid nitrogen and cold water (4-10 $\left.{ }^{\circ} \mathrm{C}\right)$. The cell suspension was sonicated by 3 bursts of $30 \mathrm{~s}$ each at $60 \%$ maximal power and then centrifuged at $10,000 \mathrm{~g}$ for 20 min. The inclusion bodies were suspended in $2 \mathrm{M} \mathrm{MgCl}_{2}$ buffer with DNase $(20 \mathrm{ng} / \mathrm{ml})$ and RNase $(6 \mathrm{ng} / \mathrm{ml})$. The inclusion bodies were again washed with distilled water to remove contaminations with salt and detergent, and centrifuged at 12,000 rpm for $30 \mathrm{~min}$, and the pellets containing proteins in the form of purified inclusion bodies were stored for further studies. To determine the effect of $\mathrm{pH}$ on solubility of the recombinant protein, aliquots of the purified inclusion bodies ( $2 \mathrm{mg}$ of cell pellet) were solubilized in STE buffer (250 mM sucrose, $5 \mathrm{mM}$ Tris, and $2 \mathrm{mM}$ EGTA, $\mathrm{pH}$ =7.4) containing $2 \mathrm{M}$ urea at different $\mathrm{pH}$ conditions ( $\mathrm{pH}: 3-12$ ). Both supernatant and pellet were individually analyzed by SDSPAGE and the amount of solubilization was assessed in different $\mathrm{pH}$ conditions by spectrofluorometry.

Solubilization of the recombinant GFP (+36)-2A-E7 protein in various concentrations of $\mathrm{NaCl}$

At optimal conditions, the harvested bacterial cells in $\mathrm{OD}_{600}$ $=1.5$ were suspended in lysis buffer including $\mathrm{NaCl}$ with different doses of $100 \mathrm{mM}, 300 \mathrm{mM}, 500 \mathrm{mM}, 1 \mathrm{M}, 1.5 \mathrm{M}$, and $2 \mathrm{M}$. The cell suspension was sonicated by 3 bursts of $30 \mathrm{~s}$ each at 60 $\%$ maximal power and then centrifuged at $10,000 \mathrm{~g}$ for $20 \mathrm{~min}$. The supernatants were individually analyzed, and the amount of solubilization was measured at different concentrations of $\mathrm{NaCl}$ by spectrofluorometry.

\section{Optimal conditions for the highest level of protein solubility}

The bacterial cells expressing the recombinant GFP $(+36)-2 \mathrm{~A}-$ $\mathrm{E} 7$ protein were grown in Ty $2 \mathrm{X}$ medium at $37^{\circ} \mathrm{C}$ to mid-log phase $\left(\mathrm{OD}_{600}=0.5\right)$ and induced by the addition of IPTG inducer to a final concentration of at least $0.5 \mathrm{mM}$ at $16^{\circ} \mathrm{C}$ for 20 hours. The cells were harvested at $6,000 \mathrm{rpm}(8000 \mathrm{~g})$ for $5 \mathrm{~min}$ at $4{ }^{\circ} \mathrm{C}$. The cell 
106-112

pellet was resuspended in $15 \mathrm{ml}$ of ice-cold buffer A per $500 \mathrm{ml}$ culture, sonicated for 5 second, and incubated on ice for $30 \mathrm{~min}$. The lysate was centrifuged at $10,000 \mathrm{rpm}$ for $15 \mathrm{~min}$ at $4{ }^{\circ} \mathrm{C}$. The cell pellet was resuspended in $15 \mathrm{ml}$ of buffer A containing Triton 10X and Tween $20 \%$, sonicated for 5 second and incubated on ice for $30 \mathrm{~min}$. After harvesting, the lysate was centrifuged at 10,000 rpm for $15 \mathrm{~min}$ at $4{ }^{\circ} \mathrm{C}$ and the cell pellet was resuspended in 15 $\mathrm{ml}$ of buffer A containing 1\%2ME and was repeated with buffer A containing DNase and RNase $(1 \mathrm{U} / \mathrm{mL})$. After harvesting, the lysate was centrifuged at $10,000 \mathrm{rpm}$ for $15 \mathrm{~min}$ at $4{ }^{\circ} \mathrm{C}$, the cell pellet was resuspended in $15 \mathrm{ml}$ of buffer A containing $1 \mathrm{M}$ urea that did not lyse the inclusion bodies, but solubilized cell debris and finally, the remaining proteins were sonicated for 5 second and incubated on ice for $30 \mathrm{~min}$. The previous step was repeated with $2 \mathrm{M}$ urea. Again, the inclusion body pellet was resuspended in buffer A containing the $4 \mathrm{M}$ urea and $\mathrm{pH}=11$ that solubilized the recombinant protein in the inclusion bodies while the ureasolubilized protein was rotated at $4{ }^{\circ} \mathrm{C}$ for $30 \mathrm{~min}$ and finally, the supernatant was collected. The supernatant containing the recombinant GFP (+36)-2A-E7 protein was loaded onto a Ni-NTA spin column and the flow-through was collected. Then, the Ni-NTA spin column was washed with $600 \mu \mathrm{l}$ buffer $\mathrm{A}$ and $3 \mathrm{M}$ urea. The wash step was repeated with $2 \mathrm{M}$ urea and $1 \mathrm{M}$ urea, respectively. Finally, the protein was eluted with buffer A and $200 \mathrm{mM}$ imidazole. The protein samples in both soluble and insoluble forms were analyzed by SDS-PAGE, concentrated and stored at $-80^{\circ} \mathrm{C}$.

\section{Cell culture}

Human embryonic kidney cells (HEK-293T) were cultured in Dulbecco's Modified Eagle's Medium (DMEM, Gibco) supplemented with $10 \%$ fetal bovine serum (FBS, Gibco) at $37{ }^{\circ} \mathrm{C}$ in presence of $5 \% \mathrm{CO}_{2}$ atmosphere. After several passages using trypsin-EDTA, the proliferated cells were counted by trypan Blue $1 \mathrm{X}$ with hemocytometer and divided into 24-well plate.

\section{Transfection of the recombinant protein into HEK-293T cells}

The day before transfection, the $0.4-0.6 \times 10^{5}$ cells were counted and seeded into 24 -well plates. The optimal cell confluency for effective transfection was considered $70-80 \%$. After the growth of HEK-293T cells to $80 \%$ confluency, the medium was replaced by serum-free medium and then $2 \mu \mathrm{g}$ of the recombinant protein in both soluble and insoluble forms was applied to each well. After $1 \mathrm{~h}$ incubation at $37^{\circ} \mathrm{C}$, the cells were supplemented with fresh RPMI, $5 \%$ FCS in a total volume of $200 \mu$ medium without removal of the complexes, and were further incubated for $3 \mathrm{~h}$ at 37 ${ }^{\circ} \mathrm{C}$. Then, the cells were treated with trypsin-EDTA, harvested by centrifugation and resuspended in PBS $1 \mathrm{X}$. The percentage of transfected cells using the recombinant +36 GFP-2A-E7 protein was monitored by fluorescence microscopy (Envert Fluorescent Ceti, Korea) and also quantified by a flow cytometer (Partec, Germany). All data were obtained in two independent experiments. Statistical analysis (Student's t-test) was performed by Prism 5.0 software (GraphPad, San Diego, California, USA) to analyze the percentage of protein delivery using flow cytometry. The value of $\mathrm{p}<0.05$ was considered statistically significant.
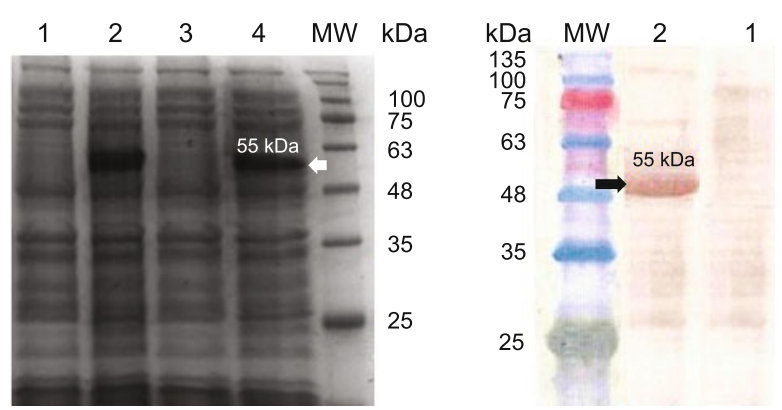

Fig. 1. A) Expression of GFP (+36)-2A-E7 protein in E. coli expression system. The fusion protein migrated as a clear band of $\sim 55 \mathrm{kDa}$ in SDS-PAGE. Lane 1 \& 3: Before induction, Lane 2 \& 4: After induction; B) Identification of the recombinant protein by western blot analysis using anti-E7 monoclonal antibody. Lane 1: Before induction, Lane 2: After induction. MW is molecular weight marker (pre-stained protein ladder, 10-180 kDa, Fermentas).

\section{Results}

\section{Cloning and expression of pET-GFP (+36)-2A-E7}

The synthesized 2A-E7 DNA was subcloned into the pET-GFP $(+36)$ vector. For confirmation of the recombinant clones, the purified pET-GFP (+36)-2A-E7 was digested by NdeI/ NotI restriction enzymes and indicated an approximately $1120 \mathrm{bp}$ band on agarose gel related to GFP-2A-E7. Then, the expression of GFP (+36)2A-E7 was performed in E. coli Rosetta strain. The recombinant protein migrated as a band of $\sim 55 \mathrm{kDa}$ on SDS-PAGE. Westernblotting analysis showed that recombinant GFP $(+36)-2 \mathrm{~A}-\mathrm{E} 7$ protein reacted with anti-E7 antibody indicating the correct conformational structure of the recombinant protein produced in Rosetta strain. The data demonstrated the clear band of $\sim 55 \mathrm{kDa}$ for GFP (+36)-2A-E7 protein using DAB substrate (Fig. 1).

\section{Solubility assay}

The harvested cells from protein expression were suspended in PBS1X followed by sonication and incubation on ice for $30 \mathrm{~min}$

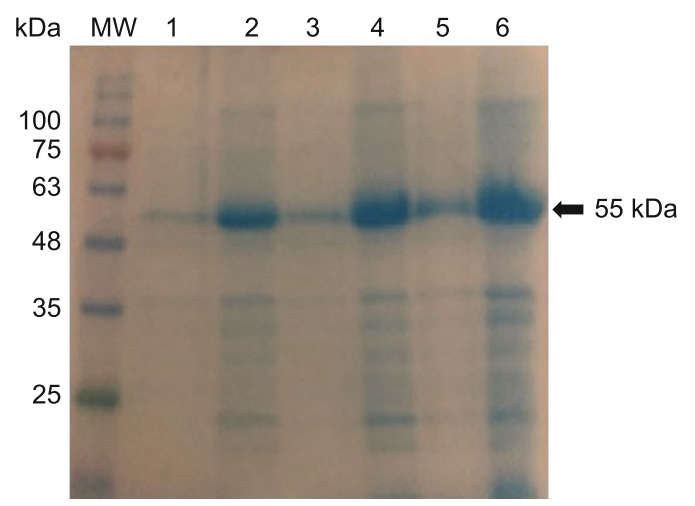

Fig. 2. Determination of protein solubility: Lane 1, 3 \& 5: Soluble fraction (supernatant); lane 2, 4 \& 6: Insoluble fraction (pellet or inclusion body). MW is molecular weight marker (pre-stained protein ladder, 10-180 kDa, Fermentas). 


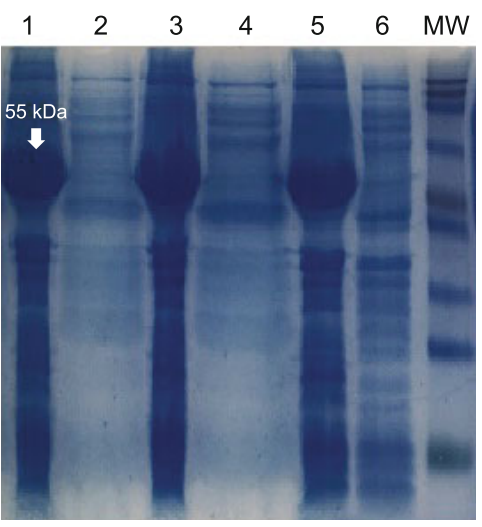

Fig. 3. Protein expression in bacterial cultures induced with $0.5 \mathrm{mM}$ (Lane 1\& 2), $0.1 \mathrm{mM}$ (Lane $3 \& 4$ ) and 1 mM IPTG (Lane $5 \&$ 6) on SDS-PAGE: The bacterial cells were collected at $37^{\circ} \mathrm{C}$ and $3 \mathrm{~h}$ after induction with IPTG. Lane 1, 3 \& 5 are after induction with IPTG, and Lane 2, $4 \& 6$ are before induction with IPTG. MW is molecular weight marker.

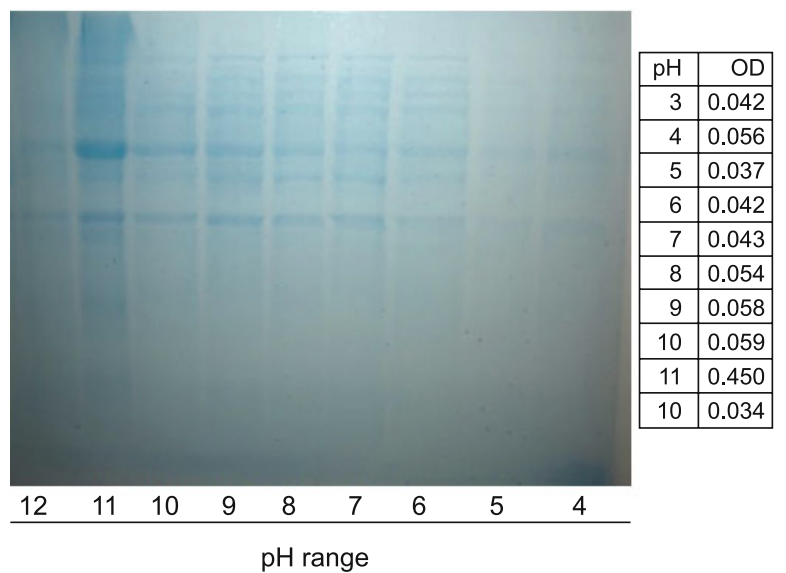

Fig. 4. The effects of different $\mathrm{pH}$ conditions on protein solubility in SDS-PAGE as well as $\mathrm{OD}_{480}$ determined by spectrofluorometry.

and this process was repeated three times. The supernatants and pellets were analyzed by SDS-PAGE. The results indicated that the recombinant GFP (+36)-2A-E7 was insoluble and available in pellet fraction (Fig. 2). It was interesting that after a repeated sonication, there was a little amount of protein in soluble form. Indeed, the time of exposure to ultrasound was important.

The effects of temperature and inducer dose on protein solubility

Our data indicated that there is a high level of protein expression in bacterial cultures induced with $0.5 \mathrm{mM}$ IPTG on SDS-PAGE (Fig. 3). Additional induction experiments were also performed using 0.1 and $1 \mathrm{mM}$ IPTG and the levels of protein expression were similar to $0.5 \mathrm{mM}$ IPTG. After determination of IPTG dose and for higher level of expression, the cells were grown at different temperatures $\left(37,28\right.$ and $\left.16^{\circ} \mathrm{C}\right)$ following induction with IPTG $(0.5 \mathrm{mM})$ to obtain the amount of soluble protein. The time of expression for the induced cultures grown at 37,28 and

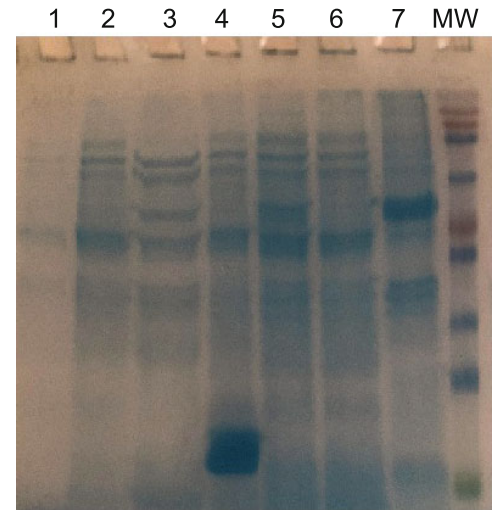

Fig. 5. Optimal conditions for the highest level of the protein solubility: Lane 1-3: buffer A with different components (Triton 10X, Tween 20 and DNase/ RNase), Lane 4 \& 5: buffer $A$ with $1 \mathrm{M}$ urea, Lane 6 \& 7: buffer $A$ with $4 \mathrm{M}$ urea and $\mathrm{pH}=11$.

$16{ }^{\circ} \mathrm{C}$ were 3,5 and $20 \mathrm{~h}$, respectively. The pellets were provided in $\mathrm{OD}_{600}=1.5$ and lysed. Then, the aliquots of supernatant and pellet were analyzed on $12 \%$ SDS-PAGE. Optimum conditions were determined by evaluating the solubility of protein by spectrofluorometry (Tab. 1). The results indicated that the amount of soluble protein expressed by $0.5 \mathrm{mM}$ IPTG at $20 \mathrm{~h}$ after induction and $16^{\circ} \mathrm{C}$ was higher than that in other conditions. Based on the mentioned results, the growth at $16{ }^{\circ} \mathrm{C}$ after induction using $0.5 \mathrm{mM}$ IPTG was suitable for high level of protein solubility. However, high level of expression was observed at $37^{\circ} \mathrm{C}$ and 0.5 $\mathrm{mM}$ IPTG for production of the recombinant GFP $(+36)-2 \mathrm{~A}-\mathrm{E} 7$ protein as insoluble aggregate (inclusion bodies) without soluble form of protein.

The effect of $\mathrm{pH}$ on solubilization of the recombinant GFP (+36)2A-E7 protein

Based on SDS-PAGE analysis, the use of $4 \mathrm{M}$ urea with $\mathrm{pH}=1$ 1 in buffer A was more suitable for providing high levels of protein solubility. Figure 4 shows the effects of different $\mathrm{pH}$ conditions on protein solubility in SDS-PAGE, as well as $\mathrm{OD}_{480}$ determined by spectrofluorometry.

The effect of different concentrations of $\mathrm{NaCl}$ on protein solubility

Based on the results measured by spectrofluorometry, different concentrations of $\mathrm{NaCl}$ in buffer $\mathrm{A}$ did not have any effect on protein solubility. The ODs for $\mathrm{NaCl}$ concentrations of 100,300 , 500, 1000, 1500 and $2000 \mathrm{mM}$ were 1.77, 1.98, 1.85, 1.99, 1.96 and 1.95 , respectively.

Optimal conditions for the highest level of the protein solubility

The results showed that GFP (+36)-A2-E7 has no solubility in buffer A containing Triton 10X, Tween 20 and DNase/ RNase as shown in Figure 5. We had poor solubility in buffer A containing $1 \mathrm{M}$ urea. The inclusion bodies were resuspended in buffer A containing the $4 \mathrm{M}$ urea, $\mathrm{pH}=11$ and the supernatant of GFP 
106-112

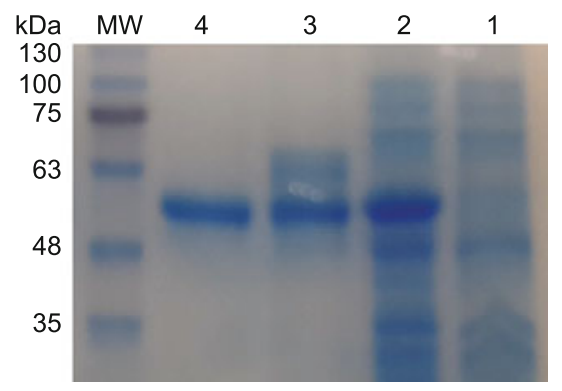

Fig. 6. The purified +36 GFP-A2-E7 protein: Lane 1: before induction, Lane 2: after induction, Lane 3 \& 4: the purified protein. MW is molecular weight marker (pre-stained protein ladder, 10-180 kDa, Fermentas).

(+36)-A2-E7 protein was collected and further purified with 200 $\mathrm{mM}$ Imidazole to transfect into the cells (Fig. 6).

Delivery of the purified GFP (+36)-A2-E7 protein into mammalian cells

Flow cytometry analysis indicated that the delivery of the purified protein with the highest level of solubility $(30.21 \pm 0.9)$ was significantly higher than insoluble protein purified with $8 \mathrm{M}$ urea $(12.63 \pm 0.3)$. Indeed, the soluble form of GFP $(+36)-\mathrm{A} 2-\mathrm{E} 7$ protein could enhance its delivery into cells significantly more than the insoluble form of protein without the use of commercial transfection reagents (Fig. 7) $(\mathrm{p}<0.05)$.

\section{Discussion}

Our goal in this study was to develop a method for achieving a soluble fluorescent protein and its delivery into cell. At first, the presence of +36GFP-A2-E7 DNA fusion in pET vector was confirmed by digestion with NdeI/ NotI enzymes as a clear band of $\sim 1120$ bp migrated in agarose gel and also sequencing. The expression of +36GFP-A2-E7 protein was evaluated in two bacterial strains (Rosetta and BL21) at $37^{\circ} \mathrm{C}$. Our data showed that the recombinant +36 GFP-A2-E7 protein could be expressed in $E$. coli Rosetta strain at $3 \mathrm{~h}$ after induction. In contrast, there was no +36GFP-A2-E7 expression in BL21 strain at different times after induction. The purified $+36 \mathrm{GFP}-\mathrm{A} 2-\mathrm{E} 7$ protein migrated as a clear band of $\sim 55 \mathrm{kDa}$ in SDS-PAGE. The recombinant +36GFP-A2-E7 protein was detectable using anti-E7 antibody in western blotting as a $55 \mathrm{kDa}$ band. Our previous results indicated that +36 GFP alone could be successfully purified under native conditions with high fluorescent property and strong penetration into the cells (12). Herein, the +36GFP-A2-E7 fusion protein was purified under denaturing conditions with $8 \mathrm{M}$ urea as insoluble fraction (inclusion body). The recombinant protein had a concentration range between 0.3 and $0.5 \mathrm{mg} / \mathrm{ml}$. For obtaining a soluble or native form of fusion protein, different conditions were used to determine protein solubility. The optimum conditions were determined as buffer with $\mathrm{pH}$ $=11$ and low concentrations of urea, $0.5 \mathrm{mM}$ IPTG, and induction temperature of $16^{\circ} \mathrm{C}$ for $20 \mathrm{~h}$ incubation time. For final purification, the protein could be eluted with buffer containing $200 \mathrm{mM}$
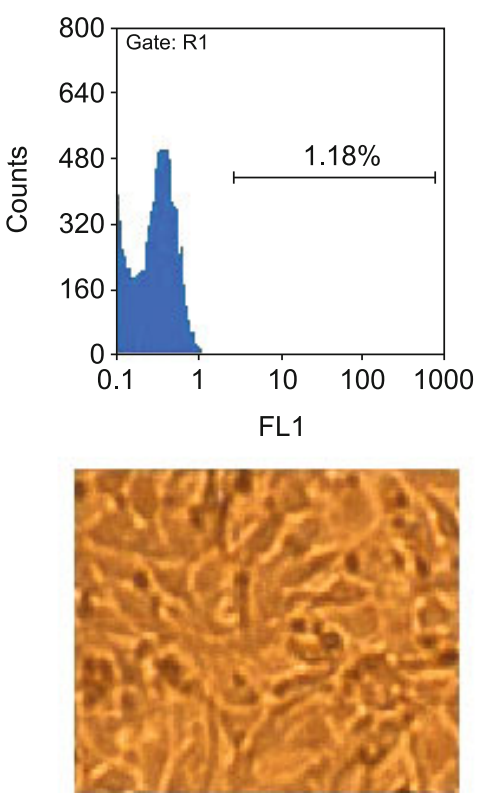

(A)
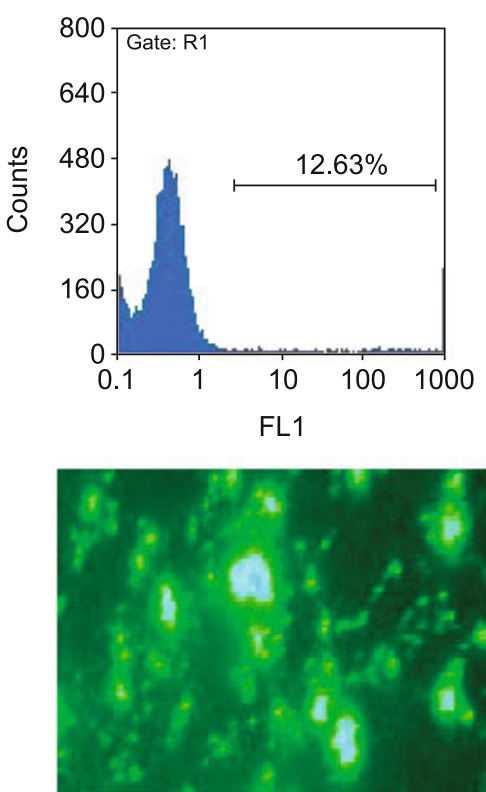

(B)
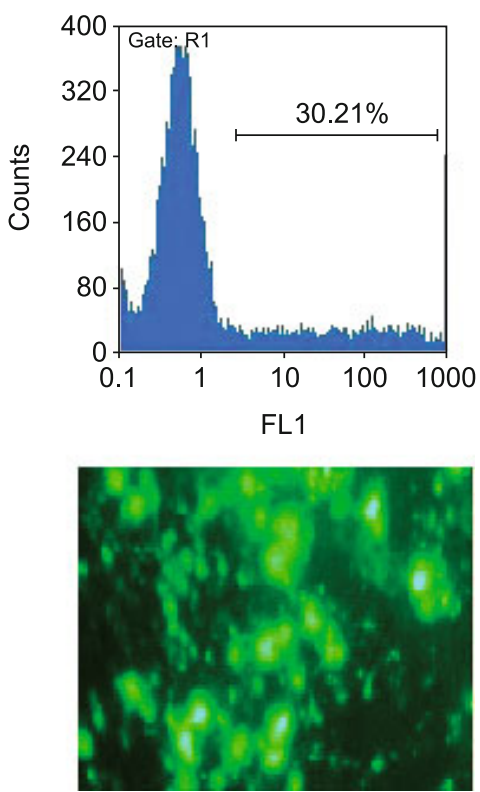

(C)

Fig. 7. Evaluation of protein delivery into the HEK-293T cells: Transfection efficiency of insoluble form (B), and soluble form (C) of protein monitored by epifluorescent microscopy and flow cytometry at $3 \mathrm{~h}$ post-transfection as compared to the negative control (A). The cells transfected by both forms of protein showed green regions with different levels. 
imidazole. Protein delivery in both insoluble and soluble forms was performed into HEK-293T cells. Our results showed that the delivery of protein in soluble form was significantly higher than that in insoluble form. The studies demonstrated that the proteins expressed in large amount or hydrophobic in nature tend to form insoluble forms. Indeed, overexpression of heterologous protein usually resulted in the formation of insoluble inclusion bodies due to the overloading of protein-folding machinery of host. Selecting the correct expression systems and protocols such as vectors, hosts and culture conditions were important for effective expression of protein in the native form. Moreover, the recovery of native proteins from insoluble inclusion bodies could be achieved by optimization of refolding conditions (19). Generally, the protein expression in different hosts is controlled by several factors such as protein size, toxicity, codon bias, protein modification and location of protein (e.g., membrane, cytoplasm, etc). However, various reports indicated that denatured proteins in the inclusion bodies have poor biological activity. Therefore, these proteins have to be solubilized and refolded from these inclusion bodies (19). Recently, optimization of different factors affecting the expression of recombinant protein in soluble fraction has been performed. The induction conditions were important for increasing the yield of the product and preventing protein accumulation in the inclusion bodies including optimization of inducer dose and induction temperature, optical density, addition of glucose or additives in media, and fusion tags for soluble protein expression and purification (19). For instance, Garcia-Fraga et al showed that lower IPTG concentrations led to the highest enzymatic activity for HsChiA1p (0.5 mM IPTG) and PtChi19p (0.25 mM), whereas very low and higher inducer concentrations resulted in an inefficient induction and a significant decrease in protein activity, respectively (20). Our study also indicated that $0.5 \mathrm{mM}$ IPTG was suitable for effective protein expression. On the other hand, the cultivation temperature could influence the activity of protein available in the inclusion bodies. Indeed, the inclusion bodies formed at low temperature were solubilized faster (in lower concentration of denaturant) than those formed at higher temperature (19). It was reported that human IFN- $\beta$ was 8.6 times more active when $E$. coli was cultured at $20^{\circ} \mathrm{C}$ as compared to cells cultured at $37^{\circ} \mathrm{C}$, although equal amounts of IFN- $\beta$ were synthesized at each temperature (21). In the current study, the expression conditions of E7 in fusion with +36 GFP were optimized. Our data showed that lower temperature after induction (i.e. growing cells for $20 \mathrm{~h}$ at $16^{\circ} \mathrm{C}$ after IPTG addition) significantly increased the protein solubility. Moreover, the phase of bacterial growth at the time of induction played a significant role in the production of soluble protein. For example, the highest yield of active protein was obtained at optical densities $(600 \mathrm{~nm})$ of 1 for HsChiA1p and 0.7 for PtChi19p, while there was a significant decrease in enzyme activity on further increase in optical density (20). We showed that optimization of inducer dose, and time and temperature of postinduction at optical density of 1.5 for +36 GFP-A2-E7 could lead to increase the solubility. The studies indicated that four factors were important for effective sonication of bacteria including the type of microorganism, temperature of the sonication buffer, exposure time to ultrasound (minutes), and composition of sonication tube (22).
As observed in our study, an increase in time of sonication may slightly improve protein solubility. In addition, inclusion bodies are very sensitive to $\mathrm{pH}$, thus, as observed in our study, the use of high $\mathrm{pH}$ led to solubilization of inclusion bodies during purification. Furthermore, we showed that the inclusion bodies could be solubilized in 4M urea along with other additives.

It was observed that un-modified fluorescent proteins could be detected by fluorescence microscopy and used as markers in living cells. The fact that fluorescent proteins can fold, even when linked to cellular proteins, directly led to the study of the biology of proteins in vivo (23). Herein, we also produced a fluorescent fusion protein using a mutant GFP with high positive charge. After optimization of protein solubility and purity, its delivery was performed in HEK-293T cells. Our results showed a considerable difference between soluble and insoluble forms of the +36GFP-A2E7 fusion protein indicating the importance of a soluble or native form for delivery into the cells. However, the insoluble form of protein could slightly penetrate into the cells, as well. Some studies also showed that bacterial inclusion bodies may possess a nativelike secondary structure (2). Altogether, these findings indicated that high levels of soluble recombinant protein could be produced in Rosetta (DE3) strain with optimization of some internal and external conditions as well as its effective delivery into mammalian cells. This fluorescent protein will be used for HPV vaccine development in the future.

\section{Conclusion}

In summary, the soluble form of +36GFP-A2-E7 fusion protein retained its biological activity and could directly penetrate into the cells without fusion tags. This study provides a method to produce sufficient amounts of soluble and active $+36 \mathrm{GFP}-\mathrm{A} 2$-E7 protein using E. coli expression system for HPV vaccine development.

\section{References}

1. Rosano GL, Ceccarelli EA. Recombinant protein expression in Escherichia coli: advances and challenges. Front Microbiol 2014; 5: 1-17.

2. Singh A, Upadhyay V, Upadhyay AK, Singh SM, Panda AK. Protein recovery from inclusion bodies of Escherichia coli using mild solubilization process. Microbial Cell Factor 2015; 14: 41.

3. Singh SM, Panda AK. Solubilization and refolding of bacterial inclusion body proteins. J Biosci Bioengineer 2005; 99 (4): 303-310.

4. Yang Z, Zhang L, Zhang Y, Zhang T, Feng Y, Lu X, Lan W, Wang J, Wu H, Cao C, Wang X. Highly efficient production of soluble proteins from insoluble inclusion bodies by a two-step-denaturing and refolding method. PLoS ONE 2011; 6(7): e22981.

5. Cabrita LD, Bottomley SP. Protein expression and refolding-A practical guide to getting the most out of inclusion bodies. Biotechnol Ann Rev 2004; 10: 31-50.

6. Villaverde A, Corchero JL, Seras-Franzoso J, Garcia-Fruitós E. Functional protein aggregates: just the tip of the iceberg. Nanomed 2015; 10(18): 2881-2891.

7. Sørensen HP, Mortensen KK. Soluble expression of recombinant proteins in the cytoplasm of Escherichia coli. Microb Cell Factor 2005; 4: 1-8. 


\section{6-112}

8. Baneyx F, Mujacic M. Recombinant protein folding and misfolding in Escherichia coli. Nature Biotechnol 2004; 22 (11): 1399-1408.

9. Sheridan DL, Berlot CH, Robert A, Inglis FM, Jakobsdottir KB, Howe JR, Hughes TE. A new way to rapidly create functional, fluorescent fusion proteins: random insertion of GFP with an in vitro transposition reaction. BMC Neurosci 2002; 3: 7.

10. Verkhusha VV, Shavlovsky MM, Nevzglyadova OV, Gaivoronsky AA, Artemov AV, Stepanenko OV, Kuznetsova IM, Turoverov KK. Expression of recombinant GFP-actin fusion protein in the methylotrophic yeast Pichia pastoris. FEMS Yeast Res 2003; 3: 105-111.

11. Katagiri Y, Ingham KC. Enhanced production of green fluorescent fusion proteins in a Baculovirus expression system by addition of secretion signal. BioTechniq 2002; 33: 24-26.

12. Motevalli F, Bolhassani A, Hesami S, Shahbazi S. Supercharged green fluorescent protein delivers HPV16 E7 DNA and protein into mammalian cells in vitro and in vivo. Immunol Lett 2018; 194: 29-39.

13. Roman A, Munger K. The papillomavirus E7 proteins. Virology 2013; 445(0): 138-168.

14. Radcliffe PA, Mitrophanous KA. Multiple gene products from a single vector: 'self-cleaving' 2A peptides. Gene Ther 2004; 11: 16731674.

15. Szymczak AL, Workman CJ, Wang Y, Vignali KM, Dilioglou S, Vanin EF, Vignali DAA. Correction of multi-gene deficiency in vivo using a single 'self-cleaving' $2 \mathrm{~A}$ peptide-based retroviral vector. Nature Biotechnol 2004; 22 (5): 589-760.
16. Bolhassani A, Zahedifard F, Taghikhani M, Rafati S. Enhanced immunogenicity of HPV16E7 accompanied by Gp96 as an adjuvant in two vaccination strategies. Vaccine 2008; 26 (26): 3362-3370.

17. Bolhassani A, Zahedifard F, Taslimi Y, Taghikhani M, Nahavandian B, Rafati S. Antibody detection against HPV16 E7 \& GP96 fragments as biomarkers in cervical cancer patients. Indian J Med Res 2009; 130 (5): 533-541.

18. Liu Z, Chen O, Wall JBJ, Zheng M, Zhou Y, Wang L, Vaseghi HR, Qian L, Liu J. Systematic comparison of 2A peptides for cloning multigenes in a polycistronic vector. Sci Rep 2017; 7: 2193.

19. Kaur J, Kumar A, Kaur J. Strategies for optimization of heterologous protein expression in E. coli: Roadblocks and reinforcements. Internat $\mathrm{J}$ Biol Macromol 2018; 106: 803-822.

20. García-Fraga B, da Silva AF, López-Seijas J, Sieiro C. Optimized expression conditions for enhancing production of two recombinant chitinolytic enzymes from different prokaryote domains. Bioprocess Biosyst Eng 2015; 38(12): 2477-2486.

21. Mizukami T, Komatsu Y, Hosoi N, Itoh S, Oka T. Production of active human interferon- $\beta$ in E. coli I. preferential production by lower culture temperature. Biotechnol Lett 1986; 8(9): 605-610.

22. Monsen T, Lovgren E, Widerstrom M, Wallinder L. In vitro effect of ultrasound on bacteria and suggested protocol for sonication and diagnosis of prosthetic infections. J Clin Microbiol 2009; 47 (8): 2496-2501.

23. Snapp E. Design and use of fluorescent fusion proteins in cell biology. Curr Protoc Cell Biol 2005; 1-17. 